\title{
Introduction to the Special Issue on Organizational Learning and Knowledge Management
}

\author{
James Y. L. Thong \\ Department of Information and Systems Management \\ Hong Kong University of Science and Technology \\ Patrick Y. K. Chau \\ School of Business \\ University of Hong Kong \\ Kar Yan Tam \\ Department of Information and Systems Management \\ Hong Kong University of Science and Technology
}

This issue is based on three outstanding articles presented at the Fourth Pacific Asia Conference on Information Systems held in Hong Kong from June 1 through 3, 2000. The articles are concerned with various knowledge management issues in the Internet era. To meet the quality of this journal, expanded versions of the conference articles went through two additional rounds of review by at least three reviewers each. We thank the authors for their perseverance and the reviewers for contributing their valuable time in reviewing the articles within an expedited time frame.

The first article, "A Conceptual Model for Virtual Organizational Learning" by Fu-ren Lin and Sheng-cheng Lin, analyzes knowledge processing in virtual organizations. The authors aim to develop insights about learning in virtual organizations and propose a conceptual model for virtual organizational learning (VOL). The VOL model is illustrated through a case study involving a teachers' community that creates knowledge, shares knowledge, and forms virtual organizations across schools' boundaries.

The second article, "Knowledge Sharing Through Intranet-Based Learning: A Case Study of an Online Learning Center" by Shan L. Pan, Ming-Huei Hsieh, and Helen Chen, addresses the management of knowledge in the Internet era. Through an exploratory case study, the authors argue that successful knowledge sharing is dependent not only on the use of particular information technologies, but also on the successful creation of a knowledge-sharing environment with a knowl-

\footnotetext{
Correspondence and requests for reprints should be sent to James Y. L. Thong, Department of Information and Systems Management, Hong Kong University of Science and Technology, Clear Water Bay, Kowloon, Hong Kong. E-mail: jthong@ust.hk
} 


\section{THONG, CHAU, TAM}

edge-management focused Human Resource Management as the coordinator of related activities.

The third article, "Internet Diffusion in Creative Micro-Businesses: Identifying Change Agent Characteristics As Critical Success Factors" by Pascale de Berranger, David Tucker, and Laurie Jones, investigates the diffusion of Internet technology among micro-businesses - very small businesses - in the creative industry. Based on interviews with eight micro-businesses, and using Everett Rogers's innovation diffusion process as the interpretive framework, the authors identify the vital roles played by knowledge providers as facilitating change agents, including infusion into the local community, provision of customized training programs, and possession of certain unique characteristics. 